\title{
DETERMINATION OF NUTATION BASED ON OBSERVATIONS WITH THE PULKOVO POLAR TUBE
}

\author{
O.V. KOTRELEVA \\ Central Astronomical Observatory, USSR Academy of Sciences \\ Pulkovo \\ 196140 Leningrad \\ USSR
}

Since 1953 regular observations have been carried out with the Polar photographic tube at Pulkovo $[1,2,3]$. A detailed description of the observational procedure, the data reduction technique, and error sources were given by Potter [4].

During 1953-1987 848 observing nights were obtained and 9911 polar distances of stars were measured (m.e. of \pm 0.05 ). The analysis of the material yelds the correction to the Woolard principal nutation term

$$
\Delta \mathrm{N}=-0.0160 \pm 0.0054 \text {, }
$$

the nutation constant thus attaining 9".1945 \pm 0.0054 for the mean observational epoch.

The results of data processing by Bakhrakh et al. (1988) for 1953-1974 are used in the present paper.

\section{References}

1. Bakhrakh, N.M. (1971) "Short period nutation from observations with the Pulkovo Polar tube", Izv. Glav. Astron. Obs. Pulkovo, No. 187, 97-108. In Russian.

2. Bakhrakh, N.M., Kotreleva, O.V., Naumov, V.A. (1988) "Observation results with the Pulkovo Polar tube in 1953 - 1974", in Yatskiv, Ya.S. (ed), The Study of the Earth as a Planet by Methods of Geophysics, Geodesy and Astronomy, Naukova Dumka, Kiev,13-15. In Russian.

3. Bakhrakh, N.M., Naumov, V.A. (1988) "The Pulkovo Polar tube", Izv. Glav. Astron. Obs. Pulkovo, No. 205, 18-19. In Russian.

4. Potter, H.I. (1956) “A method for reducing photographs obtained with a Polar tube", Izv. Glav. Astron. Obs. Pulkovo, No. 157, 101-119. In Russian. 